\title{
G-BANDING CHROMOSOME ANALYSIS OF PRAOMYS NATALENSIS (SMITH) (RODENTIA MURIDAE) FROM RHODESIA
}

\section{36 CHROMOSOME POPULATION}

\author{
N. F. LYONS 1 , C. R. GREEN 2 , D. H. GORDON ${ }^{2}$ and C. R. WALTERS 1 \\ 1 University of Rhodesia, Deportment of Pathology, Salisbury \\ and \\ 2 Blair Research Laboratory, Ministry of Health, Salisbury
}

Received 2.ix.76

\section{Summary}

Cytogenetic examination of the Rhodesian population of Praomys natalensis revealed two chromosomally distinct species, one having 32 chromosomes and the other 36 chromosomes. The G-banding patterns and suggested karyotype of the 36 chromosome species is presented here.

\section{INTRODUGTION}

Praomys (Mastomys) natalensis, commonly called the multimimmate mouse is a rodent belonging to the family Muridae. Ellerman et al (1953) noted that it was found throughout Africa south of Abyssinia (now Ethiopia) to Morocco. Matthey (1954,1958, 1966a, b) demonstrated cytogenetically that three forms exist with different chromosomal karyotypes and suggested that these represented distinct and separate species. Significant chromosomal differences were found between rodents from South Africa and samples from Central Africa. The South African species were found to have a diploid number of 36 chromosomes whilst rodents from the Central African Republic and other Central African countries had 32 and 38 chromosomes. Petter (1957) showed that the 38 chromosome species was morphologically distinct from the 32 chromosome species and was in fact Praomys erythroleucus.

During 1974 an outbreak of bubonic plague occurred in the north-west of Rhodesia from which two deaths were recorded before the disease was identified and controlled. This outbreak stimulated a programme to investigate the cytogenetics of Praomys in Rhodesia and it was found that two species exist in this country, one having 36 chromosomes and the other with 32 chromosomes. The full report of the geographic distributions of the two species will appear at a later date (Lyons et al., in preparation).

A polymorphism involving a pericentric inversion similar to that described by Matthey (1966b) was found in the 32 chromosome population. This species also showed a telocentric $\mathrm{Y}$ chromosome unlike that in the previously described 32 chromosome species. A G-banded karyotype for this species is also in preparation.

This paper presents the G-banding karyotype for the 36 chromsome species. 


\section{Materials AND methods}

Animals received an intraperitoneal injection of 0.1 per cent aqueous solution of colchicine. The dose rate was administered on an arbitrary scale with the smaller animals receiving $0.5 \mathrm{ml}$ and the larger $1.0 \mathrm{ml}$. The animals were immobilised for the injection either by wrapping them in a towel or by using anaesthetic ether. It was observed that the chromosome yield from those animals receiving ether was lower than those forcibly restrained for the injection. In addition, better results were obtained when animals were allowed to settle down in captivity for several days before injecting with colchicine and sacrificing.

Animals were sacrificed using ether or chloroform 2 hours after the colchicine administration. The limbs were carefully removed and the femurs were cut transversely at the proximal end of the shaft using a pair of scissors. A 21 gauge necdle attached to a $5 \mathrm{ml}$ hypodermic syringe filled with Hanks balanced salt solution was inserted into the shaft of the bone and pushed down to the distal end. Marrow was then gently washed out of the bone into a petri dish. This was repeated using the humerus when the shaft was large enough to accept the needle. Lumps of marrow were dispersed by repeatedly sucking them through the hypodermic needle. The marrow suspension was centrifuged at 1000 r.p.m. for 5 minutes. (Later in this survey it was found that centrifuging at 3500 r.p.m. had no detrimental effect on the cells and made it possible to tip off supernatant fluid without disturbing the button of cells and thus avoiding tedious and time-consuming pipetting.)

The supernatant fluid was removed and replaced with a 0.75 per cent aqueous potassium chloride solution and the cells resuspended with a pipette. Earlier experiments showed that potassium chloride was superior to sodium citrate for the hypotonic treatment as the chromosomes were less fuzzy and the banding was more distinct. After 15 minutes the tubes were centrifuged for 5 minutes and the supernatant removed. Freshly prepared $1: 3$ acetic acid and methanol was slowly added with constant agitation and the cells were resuspended. The tubes were again centrifuged for 5 minutes and the supernatant was removed and replaced with fresh fixative. The tubes were stoppered, kept cold where possible and stored overnight or until required.

Slides were carefully cleaned and a concentrated suspension of cells was run on to them. The best chromosome spreads were obtained when the slides were either blown dry or dried using gentle heat. Several slides of each tube wcre madc and one stained with 5 per cent Giemsa in pII 7.2 buffer for 10 minutes. Suitable slides were kept unstained at room temperature for 7 days before banding. The banding technique used is as follows:

1. Slides are prepared as above and stored for 7 days.

2. Wash in I-Tanks balanced salt solution $p H 7$ for 5 minutes.

3. Treat for $15-30$ seconds in 0.075 per cent Trypsin (1 :250, Servac) made up in Hanks balanced salt solution and adjusted to $p \mathrm{H} 7.5$ with $5 \cdot 6$ per cent sodium carbonate and used at room temperature.

4. Rinse with Hanks balanced salt solution $p \mathrm{II} 6 \cdot 0$ for 30 seconds.

5. Stain in 5 per cent Giemsa (Merck) at $p \mathrm{H} 7 \cdot 2$ for 10 minutes.

6. Rinse in water and air dry. 
1

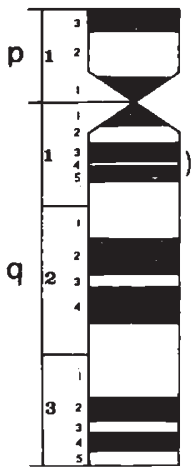

2

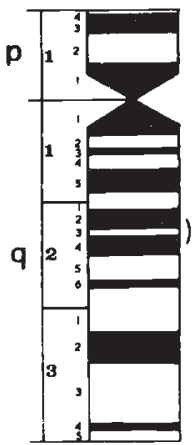

3

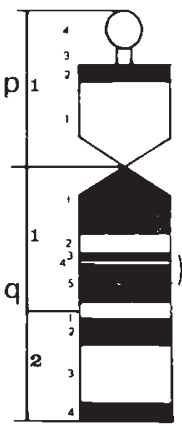

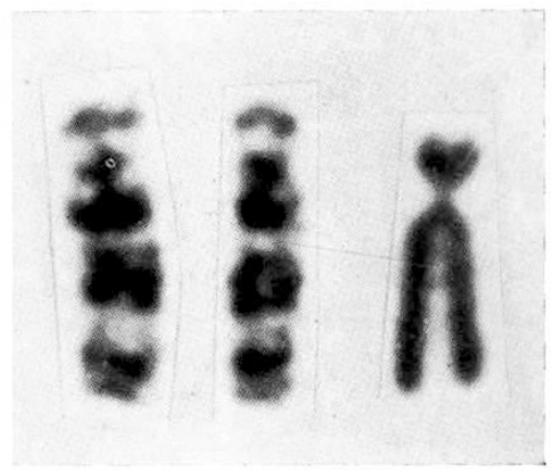
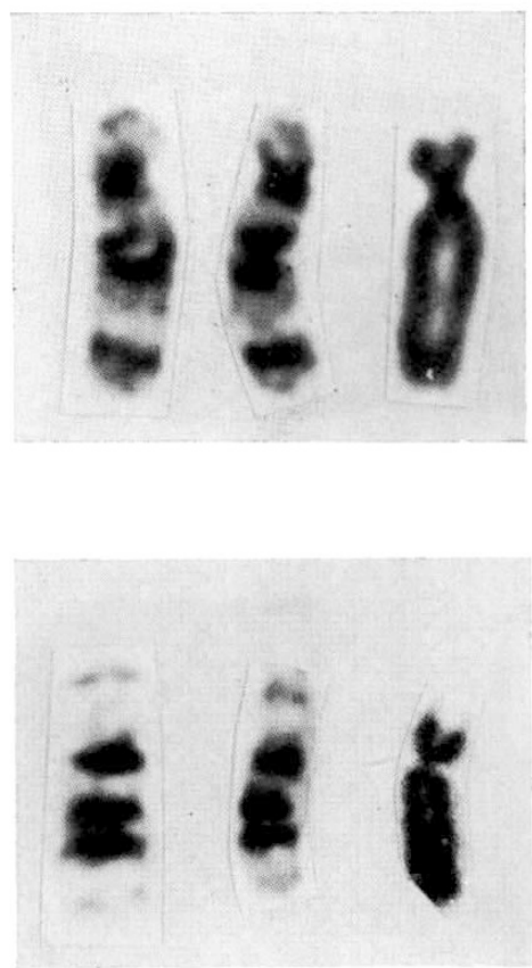

FIG. 1.-G-banding karyotype of the 36 chromosome species of Praomysnatalensis from Rhodesia. Each row shows the banding diagram produced from observations of numerous cells followed by 3 homologues of each chromosome from separate cells, 2 stained by the G-banding technique and 1 using buffered Giemsa. Bands coupled by parantheses appear as single bands on more contracted chromosomes. 
Plate II

4

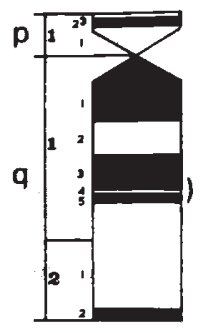

5

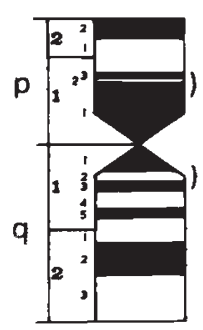

6

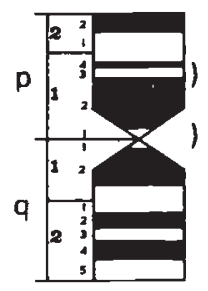

7

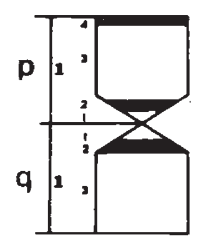

8

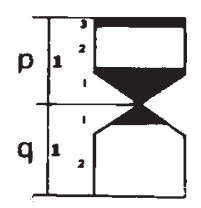

9

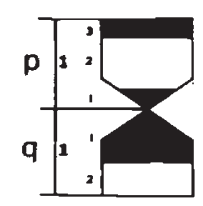

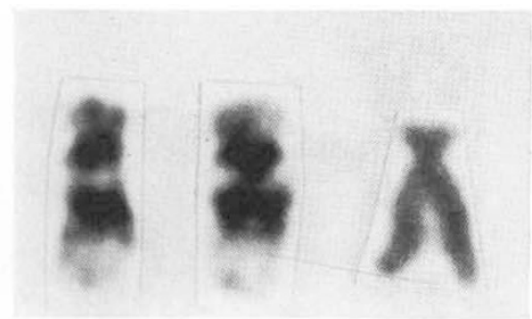
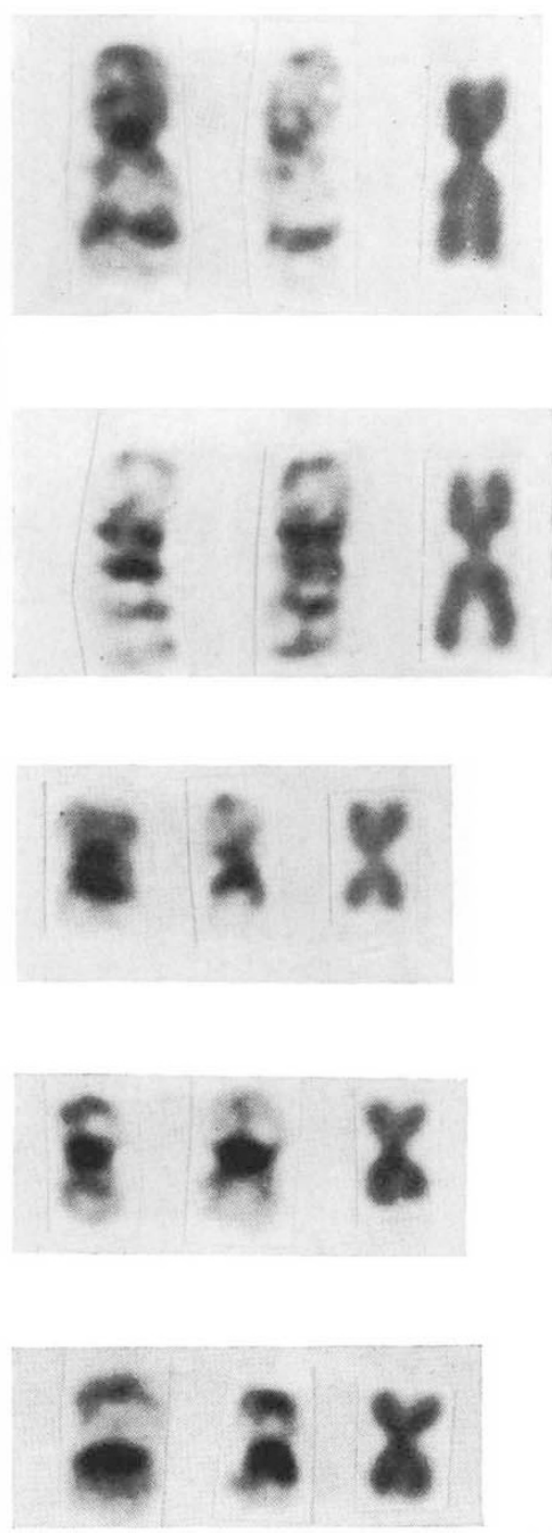
Plate III
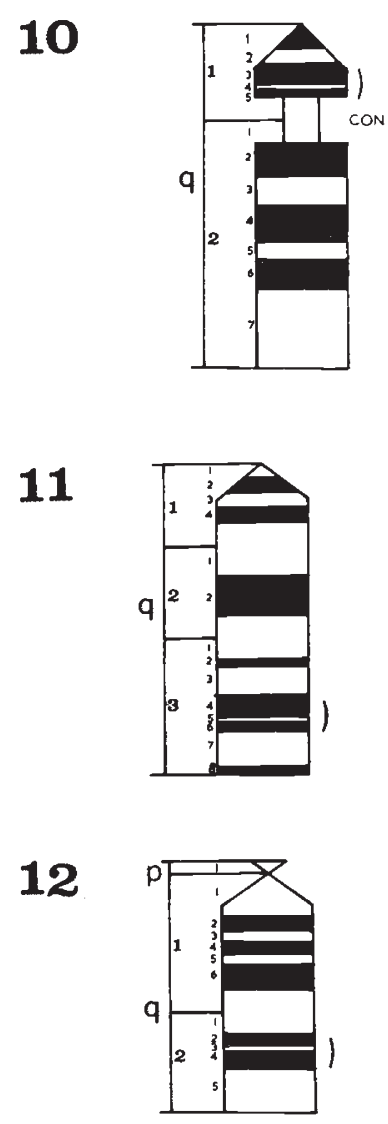

13

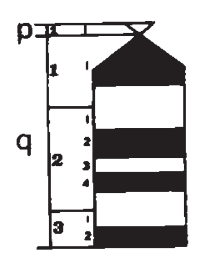

14

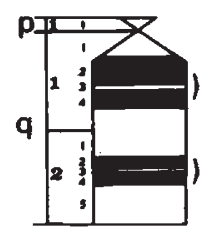

15
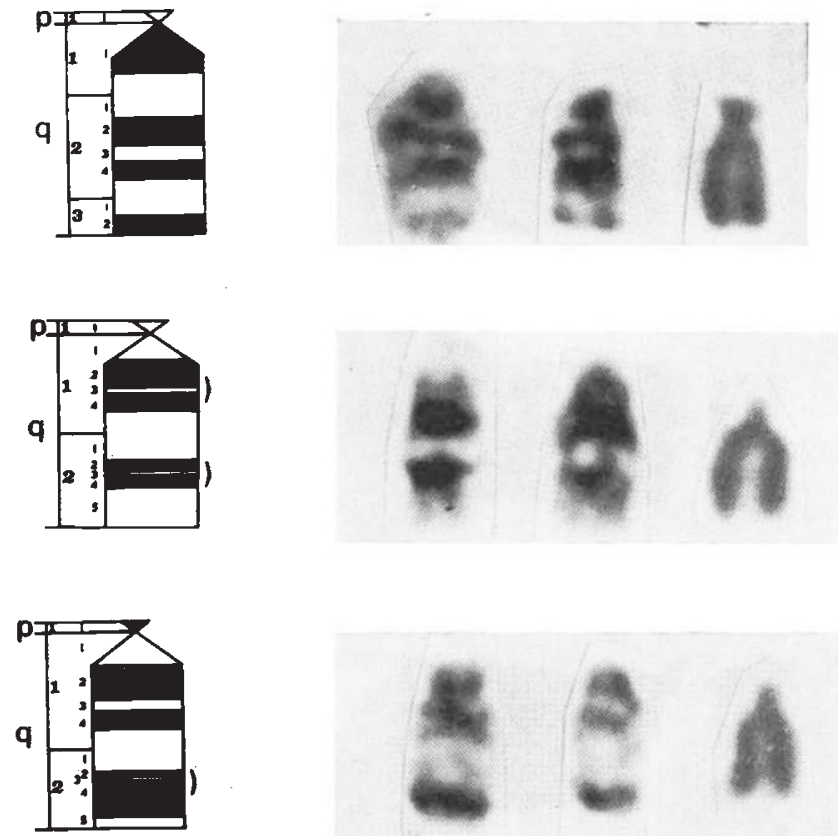
Plate IV

16
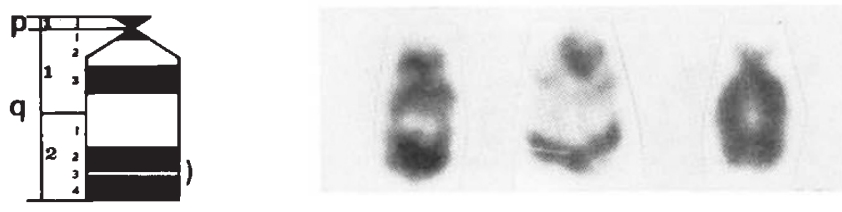

17

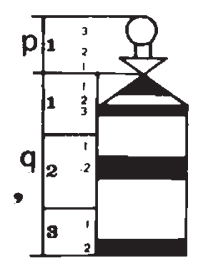

X
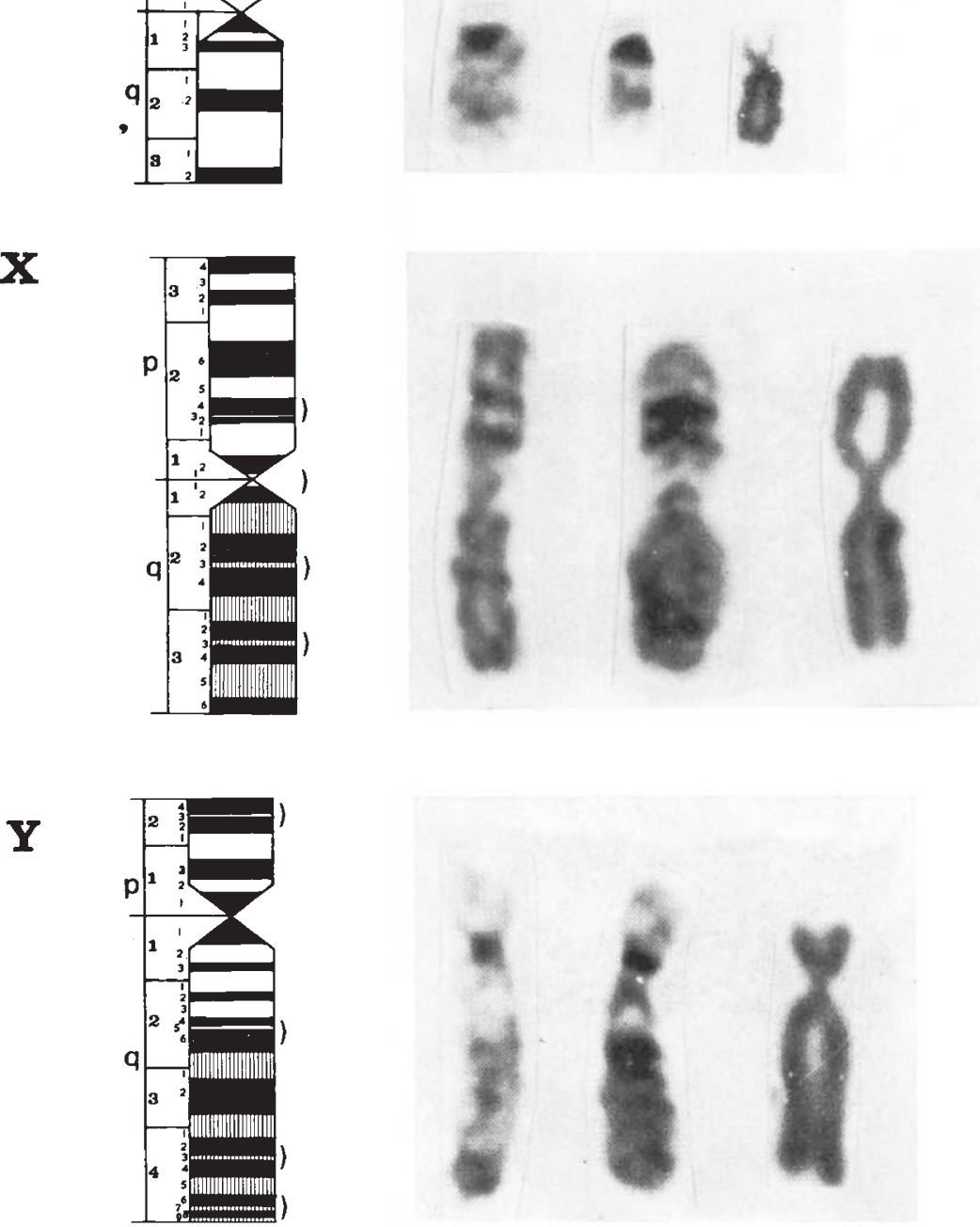
Slides may be mounted in DPX if required or examined using immersion oil and stored unmounted.

\section{Results}

The G-banding karyotype of the 36 chromosome species Praomys natalensis from Rhodesia is shown in fig. 1. The band identification used was based on the system described in the report of the Paris Conference (1972). Table 1 shows the groups to which the chromosomes are assigned in the suggested karyotype proposed here.

TABLE 1

Groups to which individual chromosomes are assigned according to shape or size in the proposed karyotype

\begin{tabular}{ccl} 
Group & $\begin{array}{c}\text { Chromosomes } \\
\text { included }\end{array}$ & \multicolumn{1}{c}{ Type } \\
A & $1-4$ & Large submetacentric \\
B & $5-9$ & Metacentric \\
C & $10-17$ & Telo or acrocentric \\
Sex & $\mathrm{X}$ and $\mathrm{Y}$ & Sex chromosomes
\end{tabular}

A simplified idiogram for practical use is shown in fig. 2.
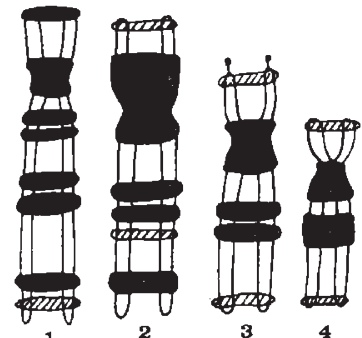

$\mathbf{A}$

4

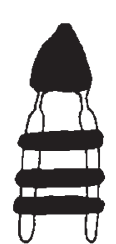

10

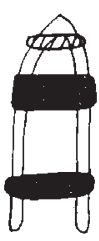

11

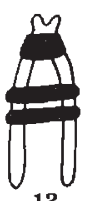

12

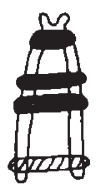

13

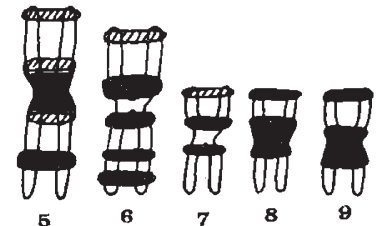

$\mathbf{B}$

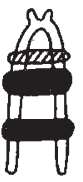

14

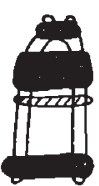

15

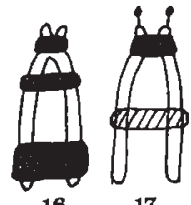

17

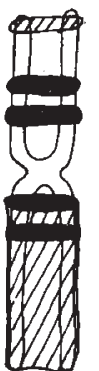

$\mathbf{x}$

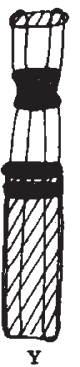

FIG. 2.--Simplified idiogram for practical use.

\section{Discussion}

A 36 chromosome species of Praomys natalensis was described by Matthey (1966a) during his investigations of a South African population of these rodents. Unfortunately, Giemsa banding was not available at that time and only gross comparisons between that group and the animals which are the subject of this paper can be made. A notable difference between the two groups is the present finding of two chromosomes with satellites Nos. 3 and 17. 
Although it is not the intention of this paper to present the geographic distribution of the distinct 36 and 32 chromosome species of Praomys in Rhodesia it is interesting to note that at the most northerly limit that the 36 chromosome population have been found, Dzivanini pan situated at Latitude $19^{\circ} 47^{\prime}$ South, Longitude $26^{\circ} 35^{\prime}$ East which is at the south-western limits of the Wankie National Park and close to the Botswana border, an overlap occurs between the two species and no hybrids have been found.

The value of Giemsa banding could prove an important tool to the zoologist interested in speciation within a genus and coupled with other genetic markers resolve some of the fundamentals of evolution.

Acknowledgment.-The authors wish to thank Mrs H. Goldsmid, Medical Artist of the University of Rhodesia, for preparing the idiograins.

\section{REFERENGES}

ELleRMAN, J. R. MORRISON-SCOTT, '1. C. S., AND HAYMAN, R. w. 1953. Southern African Mammals. Trust Brit. Mus., London.

MATTHEY, R. 1954. Nouvelles recherches sur les chromosomes des Muridae; probémes de cytologic comparèe et de taxonomie chex les Microt. Rec. Suisse Zool., 62, 163-206. MATTHEy, R. (1958). Les chromosomes et la position systématique de quelques Murinae africains (Mammalia-Rodentia). Acta trop., 15, 97-117.

MATTHEX, R. 1966a. Cytogénetique et taxonomie des Rats appartenant au sous-genes Mastomys Thomas (Rodentia-Murinae). Mammalia, 30, 105-1 19.

MATTIEY, R. 1966b. Une inversion pericentrique a l'Origine d'Un polymorphisme chromosomique non-Robertsonian dans une population de Mastomys (RodentiaMurinae). Chromosoma (Berl.), 18, 188-200.

PARIS CONFERENCE. 1971. Standardization in Human Cytogenetics (1972). Birth Defects Original Article Series. The National Foundation. Vol. 8, No. 7.

PETter, F. 1957. Remarques sur la systematique des Rattus fricains et description d'une forme nouvelle de l'Air. Mammalia, 21, 125-132. 